\title{
1 An optimisation strategy for evaluating modified Cam clay 2 parameters using self-boring pressuremeter test data
}

\section{Accepted for publication in Canadian Geotechnical Journal on 04/10/2018}

5 F.M. Gaone

6 Centre for Offshore Foundation Systems, University of Western Australia, Perth, Western

7 Australia, Australia

8 J. P. Doherty

9 School of Civil, Environmental and Mining Engineering, University of Western Australia, 10 Perth, Western Australia, Australia

11 S. Gourvenec

12 Faculty of Engineering and the Environment, University of Southampton, UK

\section{ABSTRACT}

This paper presents an efficient, practical and automated strategy for deriving Modified Cam Clay parameters from undrained self-boring pressuremeter (SBPM) data. A mixed approach involving a parametric sweep and numerical optimisation is used, with a focus on parameter groups that dominate the Modified Cam Clay response in undrained cavity expansion. The proposed technique is illustrated using data from SBPM tests carried out in soft estuarine clay. The resulting parameters are used to back analyse large scale foundation load tests and are shown to provide an excellent match to the measured foundation response.

\section{INTRODUCTION}

Accurate prediction of foundation settlement is increasingly important in onshore and offshore geotechnical design. Onshore, reducing land space requires construction on non-ideal soils or above buried infrastructure while offshore, foundation footprints must be minimised to facilitate installation while ensuring tolerances on attached quasi-rigid infrastructure, such as pipelines and spools, are not compromised. 
Despite advances in testing and modelling techniques, there is considerable evidence to show that there has been little genuine improvement in our ability to forecast foundation settlement over the past few decades. For example, in a recent international foundation prediction exercise, engineers were provided with extensive high quality laboratory and in situ test data and asked to forecast the undrained loadsettlement response of a shallow foundation on soft clay to failure [1]. Fifty predictions were submitted from groups of engineers working in both industry and academia from 13 countries. The average predicted settlement under a load of 50\% of the total bearing capacity exceeded the measured settlement by more than $1000 \%$. For the $1.8 \mathrm{~m}$ square foundation, settlement predictions ranged from $0.1 \mathrm{~mm}$ to over $1200 \mathrm{~mm}$, i.e more than 4 orders of magnitude. Similar findings have previously been presented for prediction exercises involving shallow foundations on soft clayey silt [2] and for the drained response of shallow foundations on sand [3,4]. A key reason for the huge variation in predictions is attributed to the fact that deriving parameters from test data requires considerable engineering/personal judgement. Removing subjectivity in parameter selection must therefore be regarded as critical in improving prediction performance. To do this, automated parameter selection techniques are required, in which test data are the input and engineering parameters are the output. This paper presents such a technique where undrained pressuremeter data is the input and Modified Cam Clay parameters are the output.

Self-boring pressuremeter (SBPM) testing enables in situ non-linear stress-strain response to be captured at different stress levels (depths) over a large range of strain, with minimal soil disturbance. The SBPM is an advancement of the 1955 patented Ménard pressuremeter, developed in the 1970s to reduce soil disturbance caused by pre-drilling the borehole. Existing interpretation methods allow the derivation of in situ horizontal stress, stiffness parameters and undrained shear strength from pressuremeter data. These values may be used as parameters for elastic perfectly-plastic constitutive models. However, these models are inherently limited in their ability to describe real soil behaviour. Determining parameters for more advanced soil constitutive models, such as Modified Cam Clay (MCC), from SBPM data is complicated by the fact that the parameters that control the model response are not directly visible in the measured data. Therefore, numerical models that represent the boundary conditions of the field test must be created and constitutive model parameters systematically varied 
until an optimal match between test data and model response is achieved. If done manually, this process can be complex, time consuming and it is difficult to ensure an optimal set of parameters has been identified. Attempts to derive constitutive model parameters from pressuremeter test data using numerical optimisation are reported in the literature [3,4], but these approaches require the use of additional information or resources to determine a complete parameter set.

Challenges are also reported in the literature for the simpler task of deriving MCC parameters from undrained triaxial compression tests using optimisation techniques [5-10]. This challenge has since been solved with a two-step single variable optimisation approach for normally consolidated triaxial data based on 'composite' MCC parameters [11]. This paper presents a similarly efficient and automated approach for identifying an optimal or near optimal set of Modified Cam Clay parameters from undrained self-boring pressuremeter test data. The concept of the two-step single variable numerical targeted optimisation approach was adopted in this study, yet the procedure developed is inherently different to that based on triaxial compression test data [11], since the data obtained from the SBPM tests used as the input into the optimisation process is inherently different to the data that is obtained from triaxial tests and therefore requires different strategies and constraints to determine an optimised parameter set.

Our objective is to derive a set of MCC parameters that can be used to forecast the undrained loaddisplacement response of a shallow foundation. This problem is dominated by the soil strength and the shear stiffness, and less so by the volumetric stiffness (that is measured in a one-dimensional or isotropic compression test). Therefore, the MCC model was calibrated against self-boring pressuremeter data, which is strong influenced by strength and shear stiffness of the soil.

The strategy developed in this paper relies on using standard interpretation methods to derive the initial mean effective stress (from the lift off pressure) and the undrained shear strength from final slope of pressuremeter pressure-expansion curve. This information is then used to constrain the MCC parameters that link effective stress and undrained shear strength. This significantly limits the possible set of valid soil parameters and enables an organised search and single variable optimisation procedure to be established. 
In the following sections, key aspects of the self-boring pressuremeter (SBPM) tests are presented along with the numerical model to represent the field tests; the Modified Cam Clay (MCC) model is set out, with particular emphasis on the composite parameter sets utilised in the approach developed in this study; the optimisation strategy for estimating an optimal (or near optimal) set of MCC parameters from the SBPM data is then described in detail; the strategy is applied to a set of SBPM results; and finally the strategy is validated by using the resulting optimised set of MCC parameters to back-analyse the load-settlement response of a shallow foundation field test.

The self-boring pressuremeter data used in this study, along with a range of other field and laboratory test data from the site and the results of the shallow foundation load-settlement tests have been made publically available in digital form at www.geocalcs.com/datamap [12].

\section{SELF-BORING PRESSUREMETER TESTING}

Self-boring pressuremeter (SBPM) testing was carried out in soft estuarine clay at the National Field Testing Facility (NFTF) in Ballina, New South Wales, Australia as part of a wider field testing programme [13]. Figure 1 shows an aerial image of the NFTF with the positions of the SBPM tests, along with the location of other in situ characterisation tests and shallow foundation and embankment field tests.

The full SBPM programme comprised 27 tests with the newly refurbished University of Western Australia (UWA) self-boring pressuremeter [14], carried out in six boreholes between $2 \mathrm{~m}$ and $9 \mathrm{~m}$ below ground level, with and without unload-reload loops, at different loading rates and with stress holding periods to assess consolidation and creep. In this paper, eight tests from three boreholes (2, 3 and 4 in Figure 1) from depths between $2.00 \mathrm{~m}$ and $5.50 \mathrm{~m}$ are considered. These tests were selected as they did not involve unload/reload loops or stress holding periods and were carried out at a rate to ensure an undrained soil response. Details of and results from the entire programme of testing are presented in a separate publication [14]. The purpose of this paper is to set out and verify the targeted numerical optimisation strategy for determining an optimal or near optimal set of Modified Cam Clay parameters from SBPM tests for use in predicting the undrained load-settlement response of a shallow foundation. 


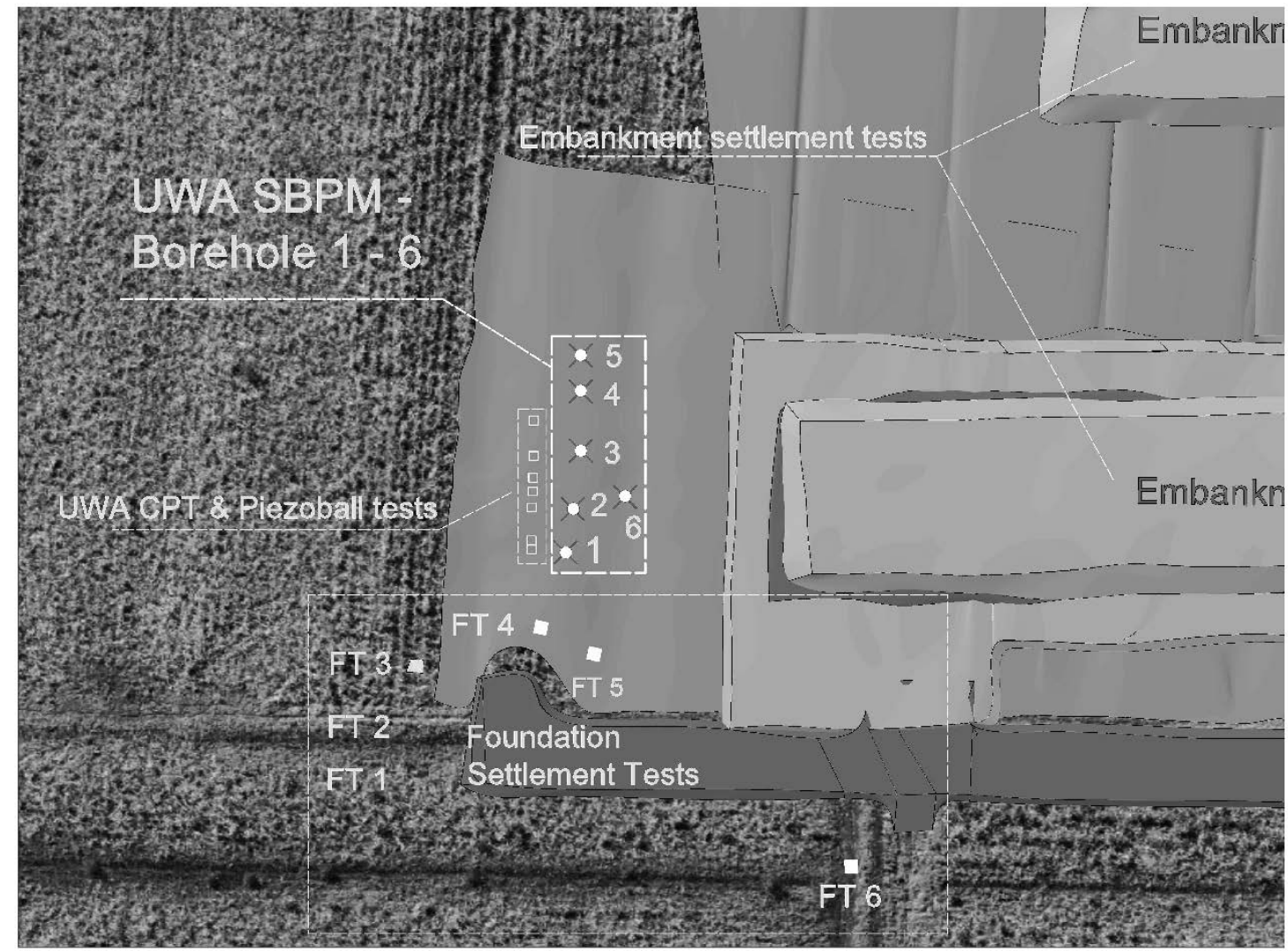

Figure 1: Aerial view of the NFTF showing the location of the SBPM tests, other in situ soil characterisation tests and foundation and embankment settlement tests.

114 A two-dimensional axisymmetric finite element model was developed to simulate the field SBPM tests

115 in order to generate the numerical responses necessary to compare with field test data. The model was 116 created with the finite element software package, Abaqus [15], and comprised 1767 8-noded quadratic

117 elements (Figure 2). The pressuremeter cavity was modelled in a soil domain extending 0.7 times the 118 height of the pressuremeter above and below the cavity and 100 times the radius of the pressuremeter 119 in the radial direction. Displacements were constrained in the vertical direction across the base and in 120 the radial direction on the outer edge. A constant pressure boundary condition was applied to the upper 121 surface to represent the overburden pressure. A parametric study was conducted to ensure that the 122 boundaries were positioned to ensure the restraints did not influence the simulation results. The 
expansion of the cavity wall was achieved by a prescribed radial pressure equal to the cavity pressure in the field tests. MATLAB and Python scripts were used to automate the variation of input parameters and post processing of output data. The soil was represented with the Modified Cam Clay model available in Abaqus (Clay Plasticity), described in the following section.

127

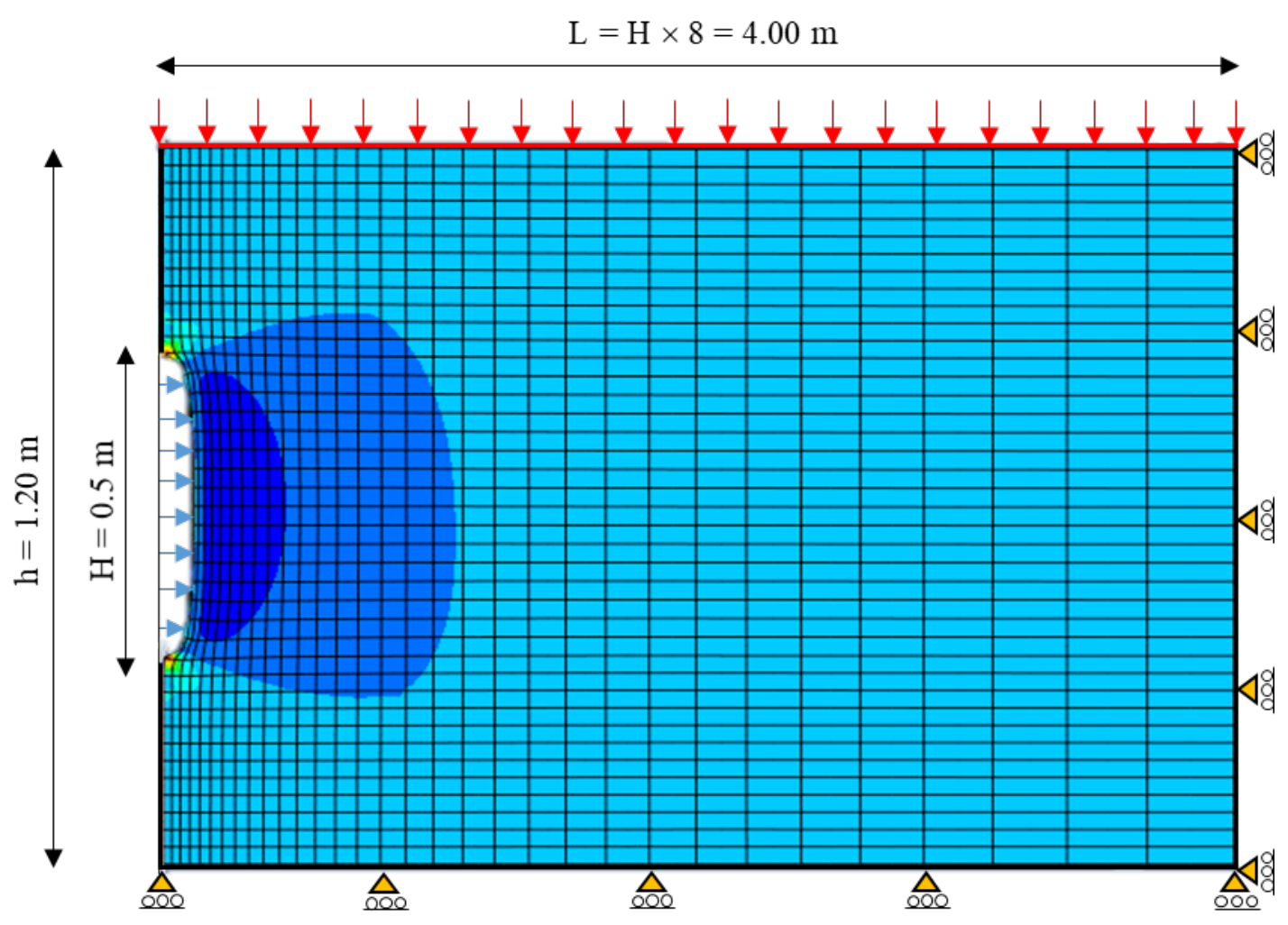

Figure 2: Finite element mesh for SBPM test simulation. 

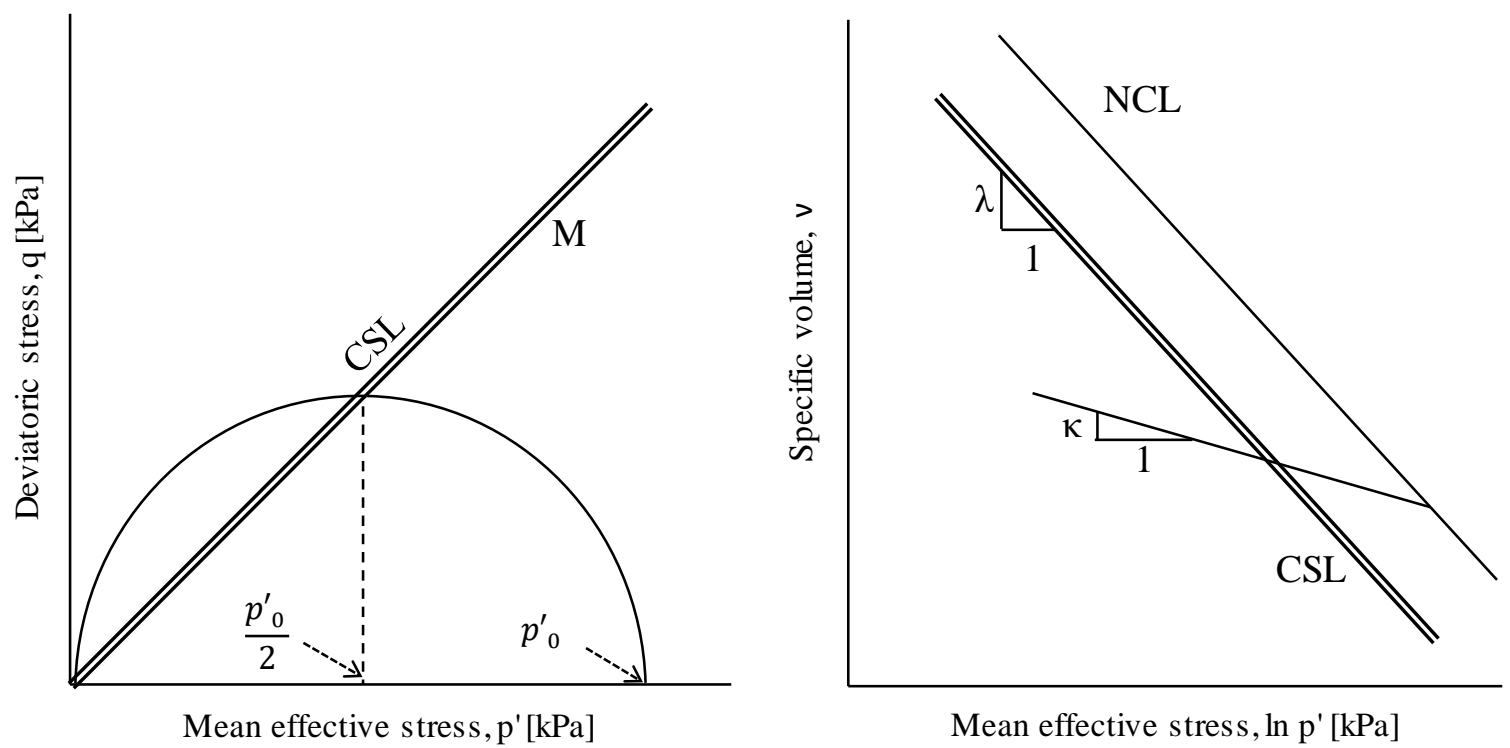

Figure 3: Modified Cam Clay representation in $p^{\prime}: q$ and $v / l n p^{\prime}$ space. $(\mathrm{CSL}=$ Critical state line; NCL

$=$ Normal compression line)

Table 1: Definition of Modified Cam Clay parameters

\begin{tabular}{ll}
\hline Parameter & Value \\
\hline$\lambda$ & Slope of the normal compression line (NCL) \\
$\kappa$ & Slope of the unload reload line \\
$v$ & Specific volume \\
$M$ & Slope of the critical state line (CSL) in $p^{\prime}: q$ plane \\
$\mu$ & Poisson's ratio
\end{tabular}

140

141 The stress state is defined under triaxial conditions by the mean effective stress, $p^{\prime}$, and the deviatoric

142 stress, $q$, where

(1)

$$
p^{\prime}=\frac{\left({\sigma^{\prime}}_{1}+2{\sigma^{\prime}}_{3}\right)}{3}
$$

and

(2)

$$
q=\left(\sigma_{1}^{\prime}-\sigma_{3}^{\prime}\right)
$$


where $\sigma_{1}^{\prime}$ and $\sigma_{3}^{\prime}$ are the major and minor principal effective stresses respectively.

145 The elliptical yield surface in the $p^{\prime}: q$ plane is defined by

$$
\frac{p_{0}^{\prime}}{p^{\prime}}=\frac{M^{2}+\eta^{2}}{M^{2}}
$$

where $p_{0}^{\prime}$ is the isotropic pre-consolidation pressure, $M$ is the slope of the critical state line and

$\eta=q / p^{\prime}$. Inside the yield surface the model is elastic, with a shear modulus given by

$$
G=\frac{3(1-2 \mu) v p^{\prime}}{2(1+\mu) \kappa}=\frac{3(1-2 \mu) p^{\prime}}{2(1+\mu) \kappa^{*}}
$$

The elastic shear stiffness can be expressed with a constant Poisson's ratio, $\mu$, and varying shear modulus, $G$, or vice versa. In this study Poisson's ratio, $\mu$ was kept constant while the shear modulus, $G$, varied with the mean effective stress, $p^{\prime}$.

The undrained shear strength can be determined from MCC parameters as

$$
s_{u}=\frac{p_{i}^{\prime}{ }_{i} M}{2}\left(\frac{R_{0}}{2}\right)^{\Lambda}
$$

Where the exponent $\Lambda$ is given by

$$
\Lambda=\frac{\lambda-\kappa}{\lambda}
$$
$p^{\prime}{ }_{0}$, and the initial mean effective stress, $p_{i}^{\prime}$

$$
R_{0}=\frac{p_{0}^{\prime}}{p_{i}^{\prime}}
$$

In the MCC formulation, the two compression indices, $\kappa$ and $\lambda$, always appear in combination with the specific volume, $v$. For an undrained response, for which $v$ is constant, this allows the number of MCC parameters to be reduced by introducing the composite parameters 
(8)

$$
\kappa^{*}=\frac{\kappa}{v}
$$

and

(9)

$$
\lambda^{*}=\frac{\lambda}{v}
$$

Noting that $\Lambda$ can also be defined in terms of these composite parameters (i.e. $\left.\Lambda=\left(\lambda^{*}-\kappa^{*}\right) / \lambda^{*}\right)$.

\section{OPTIMISATION PROCESS}

162 Optimisation problems require the search for the minimum value of an 'objective function', which measures the overall difference between numerically generated model data and measured test data. The difference between a given set of model and test data is expressed as a single scalar value, $I$. A high value of the objective function $I$ indicates a large difference between the model and test data, a value of zero indicates a perfect match. The general optimisation process is illustrated in Figure 4.

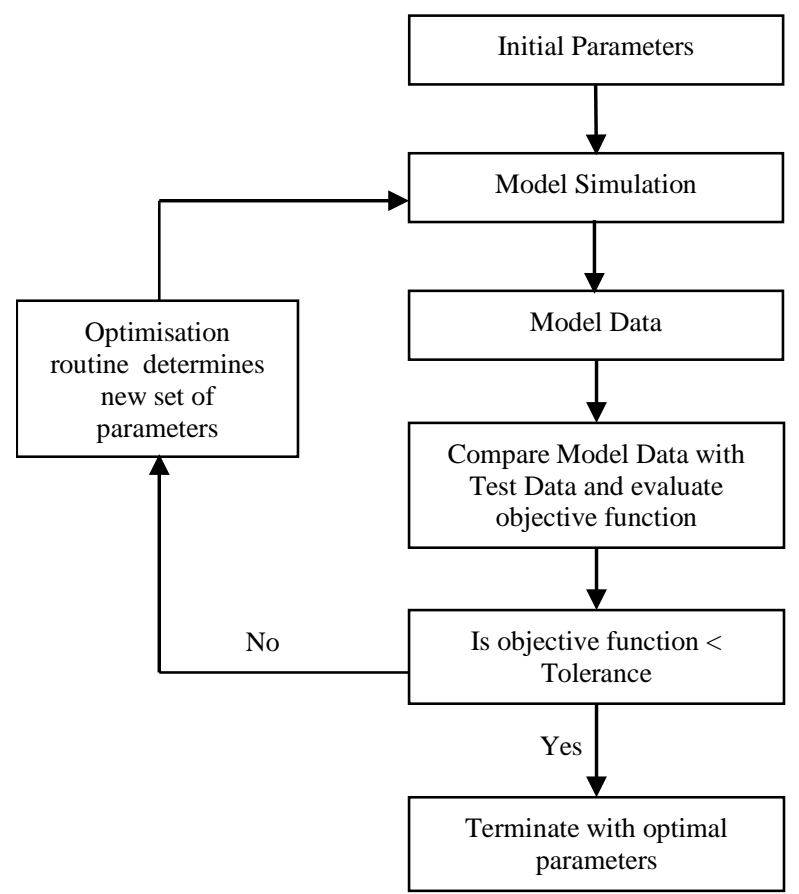

Figure 4: Flow chart showing general optimisation process.

There are a number of rational methods for comparing model and test data and computing the value of the objective function $I$. In this study, the objective function was formed by summing the minimum 


$$
I=\frac{1}{n}\left(\sum_{j=1}^{n} d_{\min }^{j}\right)
$$

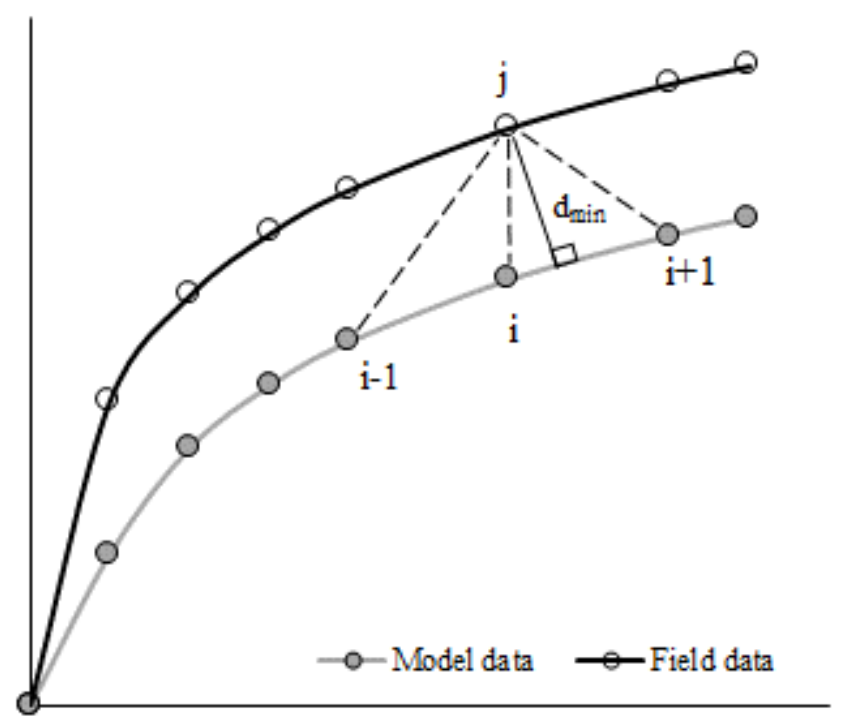

174

Figure 5: Derivation of a scalar value to describe the difference of two curves.

The advantages of using this procedure in forming the objective function are discussed in detail by [7].

\section{TARGETED NUMERICAL OPTIMISATION STRATEGY}

Overview

179 The systematic optimisation strategy developed in this study to derive a set of MCC parameters for boundary value problems that are dominated by undrained shearing using SBPM test data is described in this section. The strategy was applied to eight SBPM test results over a range of depths relevant to

182 the shallow foundation problem to which the results are later applied. The tests were selected as they did not involve unload-reload loops, or creep holds and were conducted at a strain rate that ensured undrained behaviour. Example stress-strain data for four of the selected tests are shown in Figure 6. 


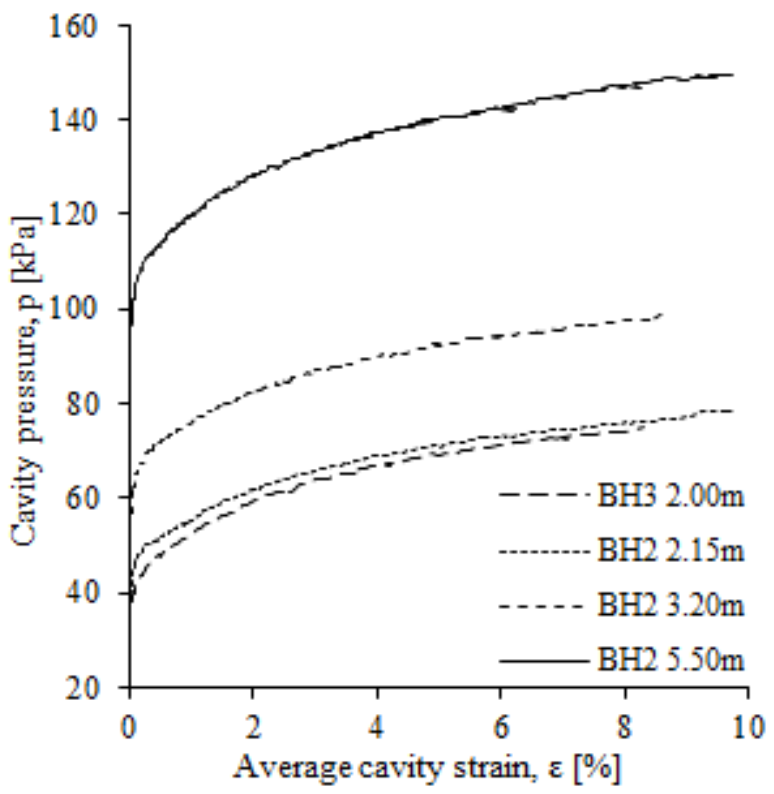

Figure 6: Cavity pressure - cavity strain response for a selection of the SBPM field tests considered in this study.

Prior to the optimisation stage, the initial mean effective stress, $p_{i}^{\prime}$, and undrained shear strength, $s_{u}$, for each test depth was calculated from well-established methods. The approaches adopted for determining $p_{i}^{\prime}$ and $s_{u}$, for this study are set out below. A sensitivity study is then presented to examine the relative influence of each MCC parameter on the computed pressuremeter response in order to reduce the parameter space for the subsequent optimisation stage. The optimisation strategy is then presented.

Mean effective stress determination

The initial mean effective stress $\left(p_{i}{ }^{\prime}\right)$ at each test depth was calculated by estimating the total vertical stress $\left(\sigma_{v}\right)$ based on the soil density and the total horizontal stress based on the lift off pressure from the SBPM data $\left(\sigma_{h}\right)$. Effective stresses were determined by subtracting the in situ static pore pressure $(u)$.

$$
p_{i}^{\prime}=\frac{\left(\sigma_{v}+2 \sigma_{h}\right)}{3}-u
$$


201 The undrained shear strength $\left(s_{u}\right)$ can be estimated from SBPM data using a well-established approach

202 ([17], [18]), describing the relationship of cavity pressure $(p)$ and volumetric strain $(\Delta V / V)$ through

$$
p=p_{l}+s_{u} \ln \left(\frac{\Delta V}{V}\right)
$$

where $p_{l}$ is the limit pressure, $\Delta V$ is the cavity volume change and $V$ is the current cavity volume $\left(V_{0}+\right.$ curve when

$$
p \geq \sigma_{h}+s_{u}
$$
infinite expansion of the pressuremeter and is given by:

$$
p_{l}=\sigma_{h}+s_{u}\left(1+\ln \left(\frac{G}{s_{u}}\right)\right)
$$

The cavity pressure versus cavity strain on a semi-logarithmic plot becomes linear as plastic strain governs, with the gradient of the slope being equal to the undrained shear strength $s_{u}$, as shown in Figure 7.

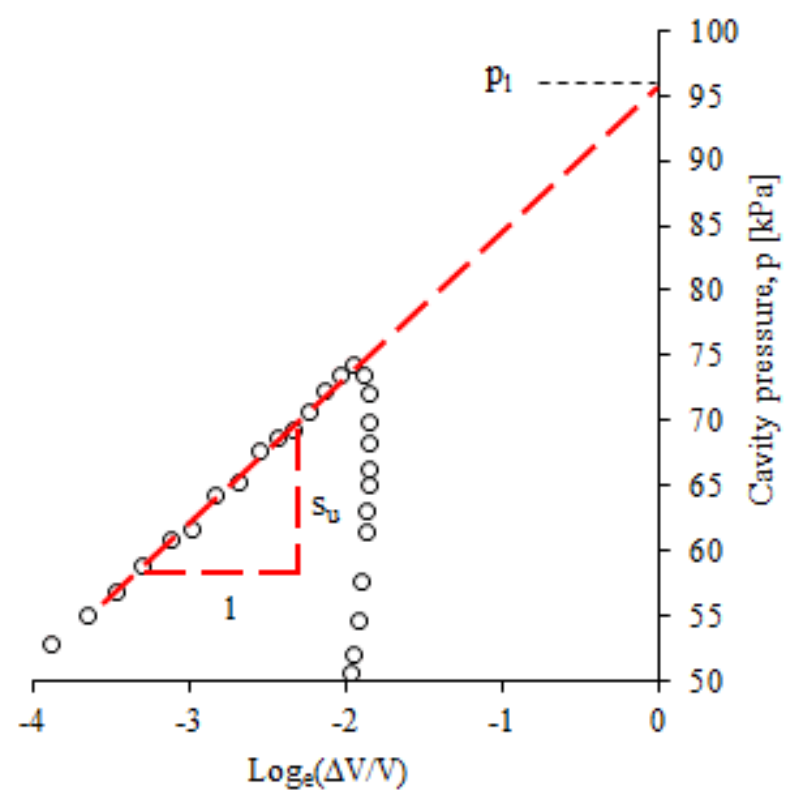

212 Figure 7: Example demonstrating the estimation of undrained shear strength $\mathrm{s}_{\mathrm{u}}$ from SBPM data. 
213 The mean effective stress and the undrained shear strength for the eight tests considered in this study

214 are given in Table 2 along with the borehole reference, depth and loading rate.

Table 2: Pressuremeter test details considered in this study.

\begin{tabular}{|c|c|c|c|c|}
\hline Borehole & $\begin{array}{c}\text { Depth } \\
{[\mathrm{m}]}\end{array}$ & $s_{u}$ & $p^{\prime}{ }_{i}$ & $\begin{array}{c}\text { Loading } \\
{[\mathrm{kPa}]}\end{array}$ \\
{$[\mathrm{kPa}]$} & $\begin{array}{c}\text { rate } \\
{[\mathrm{kPa} / \mathrm{min}]}\end{array}$ \\
\hline BH 2 & 2.15 & 10.5 & 24.5 & 10 \\
\hline BH 2 & 3.20 & 11.4 & 31.4 & 10 \\
\hline BH2 & 4.15 & 12.8 & 45.0 & 10 \\
\hline BH 2 & 5.50 & 15.3 & 50.0 & 10 \\
\hline BH 3 & 2.00 & 11.0 & 23.6 & 25 \\
\hline BH3 & 3.00 & 14.6 & 32.0 & 50 \\
\hline BH4 & 3.00 & 9.4 & 31.0 & 1 \\
\hline BH4 & 4.00 & 10.0 & 39.5 & 1 \\
\hline
\end{tabular}

Parameter sensitivity analysis

With values for undrained strength and initial mean effective stress, $s_{u}$ and $p^{\prime}{ }_{i}$, established from standard interpretation methods (as described above), the MCC formulation for undrained shear strength, given in Equation (5), can be used to constrain the possible combination of MCC parameter values $M, \Lambda$ and $R_{0}$. To develop an efficient process for evaluating these parameters, a study was carried out to examine the relative influence of these three parameters on the computed pressuremeter stress-strain response. The values used in the parametric study were constrained to fall within a typical range for soft clays [19].

226 Figure 8a shows the effect on the stress-strain response of varying the ratio $\Lambda$ (between 0.70 and 0.99 )

227 while the isotropic overconsolidation ratio was fixed to $R_{0}=1.1$. The free variable, $M$, was evaluated by re-arranging Equation (5) (see equation (15)). For the example shown in Figure 8, values of $s_{u}=15.3$ $\mathrm{kPa}$ and $p_{i}^{\prime}=50 \mathrm{kPa}$ were adopted to correspond to the test depth of $5.5 \mathrm{~m}$ (see Table 2). 


$$
M=\frac{2 s_{u}}{p_{i}^{\prime}}\left(\frac{R_{0}}{2}\right)^{-\Lambda}
$$

231 It can be seen from Figure 8a that for constant values of $p_{i}^{\prime}, R_{0}$, and $s_{u}$, changes in $\Lambda$ and $M$, over a relatively large range, have very little impact on the computed undrained stress-strain response.

233 A similar study was conducted by fixing $\Lambda=0.8$ and varying $R_{0}$ between 1.1 and 1.9 , with $M$ again 234 evaluated to satisfy $s_{u}=15.3 \mathrm{kPa}$ and $p_{i}^{\prime}=50 \mathrm{kPa}$ for the test at $5.5 \mathrm{~m}$. Curves within each figure were compared by computing I using Equation (10). It was found that the isotropic overconsolidation ratio $R_{0}$ had a more significant impact on the computed undrained pressuremeter response than the other variables, as the value of $I$ for the curves in Figure $8 \mathrm{~b}$ (in which $R_{0}$ was varied) was double that of those in Figure 8a (in which $\Lambda$ was varied).
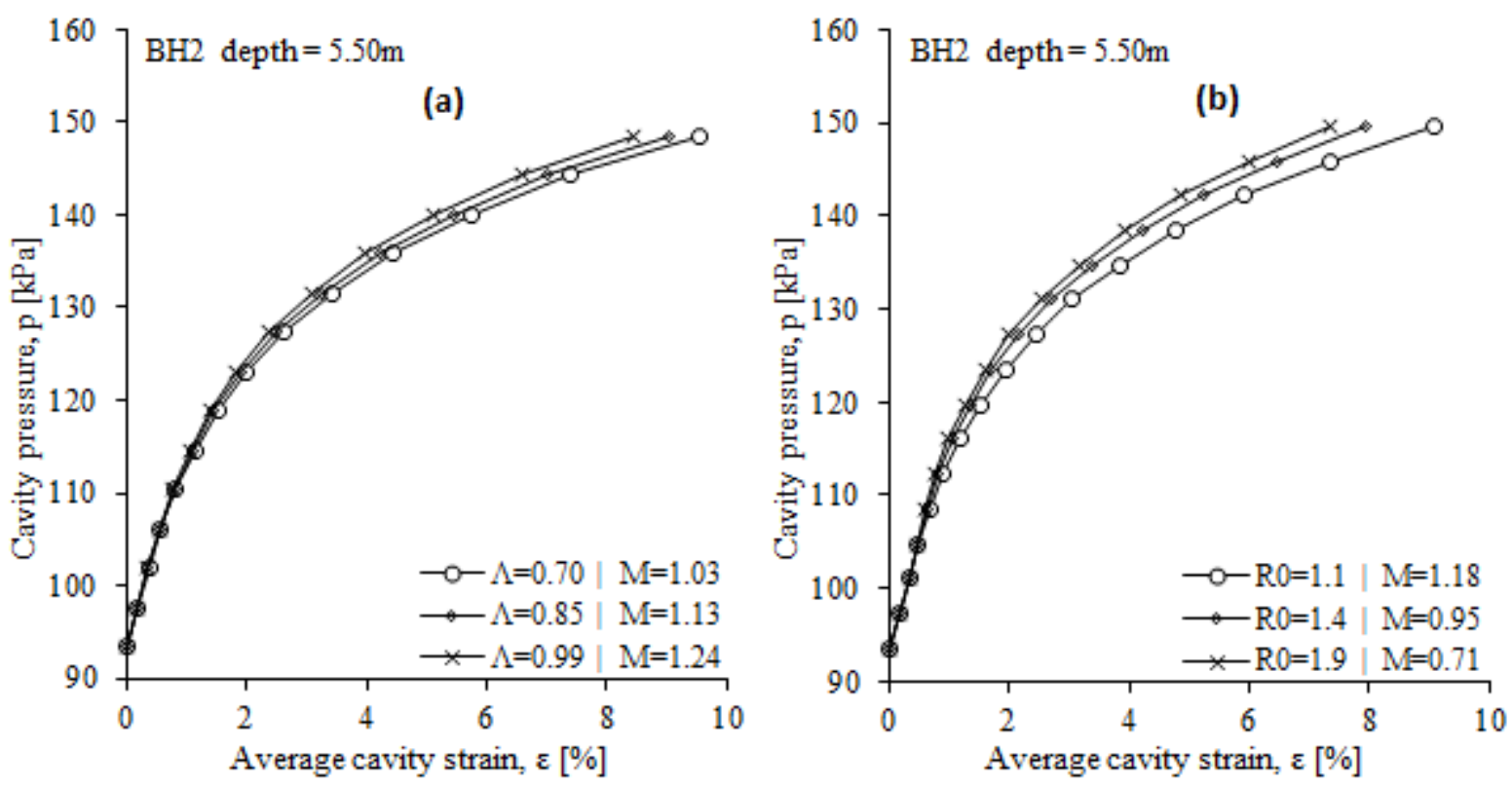

Figure 8: Parameter impact on the numerical SBPM stress-strain response

(a) of varying $M$ and $\Lambda$ with a fixed value of $R_{0}=1.1$ and (b) of varying of $R_{0}$ and $M$ with fixed value of $\Lambda$.

244 This indicates that of the three unknown parameters in the MCC formulation for undrained strength, Equation (5), $R_{0}$ has the most significant influence on the stress-strain response. Sensitivity studies 
conducted on tests at other depths resulted in similar findings. Based on this, $R_{0}$ was included in the optimisation procedure outlined below. Of the two remaining parameters (that have been shown to have minimal impact on the numerical response), $\Lambda$ typically falls in the narrowest range for soft clays [19]. Therefore, to proceed with the parameter determination process, $\Lambda$ was fixed to a representative value allowing $R_{0}$ to be varied in the parameter selection process while $M$ is determined from Equation (15). Linking these three parameters through Equation (15) constrains the search space and ensures that the resulting parameter set will give the same undrained shear strength as that determined from traditional interpretation methods [18].

The remaining MCC parameters, $\kappa^{*}$ and $\mu$ (see Table 1 ) have no influence on the undrained shear strength, but significantly impact the stiffness (see Equation (4)). Of these parameters, Poisson's ratio, $\mu$, has the narrowest range; typically, $0.1-0.4$ (a factor of 4) compared with $\kappa^{*}$ that could vary by a factor of 50. On this basis, a strategy that involved a parametric sweep over $\mu$ and the application of numerical optimisation to identify $\kappa^{*}$ is outlined below.

\section{Optimisation strategy}

The nested single variable optimisation strategy developed in this study is illustrated in Figure 9, and can be described in the following steps:

1. Estimate the initial mean effective stress, $p_{i}^{\prime}$, and the undrained shear strength, $s_{u}$, from SBPM data (as described above).

2. Set an initial value (estimate) for the composite parameter $\Lambda$ within an acceptable range.

3. Set the maximum $\left(R_{0}^{\max }, \mu^{\max }\right)$, minimum $\left(R_{0}{ }^{\min }, \mu^{\min }\right)$ and incremental values $\left(\delta R_{0}, \delta \mu\right)$ for the isotropic over consolidation ratio, $R_{0}$ and Poisson's ratio, $\mu$. To begin with set $R_{0}=R_{0}{ }^{\min }$ and $\mu=\mu^{\min }$.

4. Compute $M$ from Equation (15) for a given $p^{\prime}$, $s_{u}, \Lambda$ and $R_{0}$. 
5. Conduct single variable optimisation to compute an optimal value of $\kappa^{*}$ with $p_{i}^{\prime}, s_{u}, \Lambda, R_{0}, M$ and $\mu$ and store the value of the objective function, $I$, (Equation (10)) for the optimum value of $\kappa^{*}$.

6. If $\mu<\mu^{\max }$ increase $\mu$ by $\delta \mu$ and go to step 5 , otherwise go to step 7 .

7. If $R_{0}<R_{0}{ }^{\max }$ increase $R_{0}$ by $\delta R_{0}$ and go to step 4, otherwise go to step 8

8. The outcome is a table of parameters $\left(\Lambda, R_{0}, M\right.$ and $\mu$ and $\left.\kappa^{*}\right)$ along with the value of the objective function ( $I$ ) for each parameter set.

9. Select the set of parameters with the lowest value of $I$. 


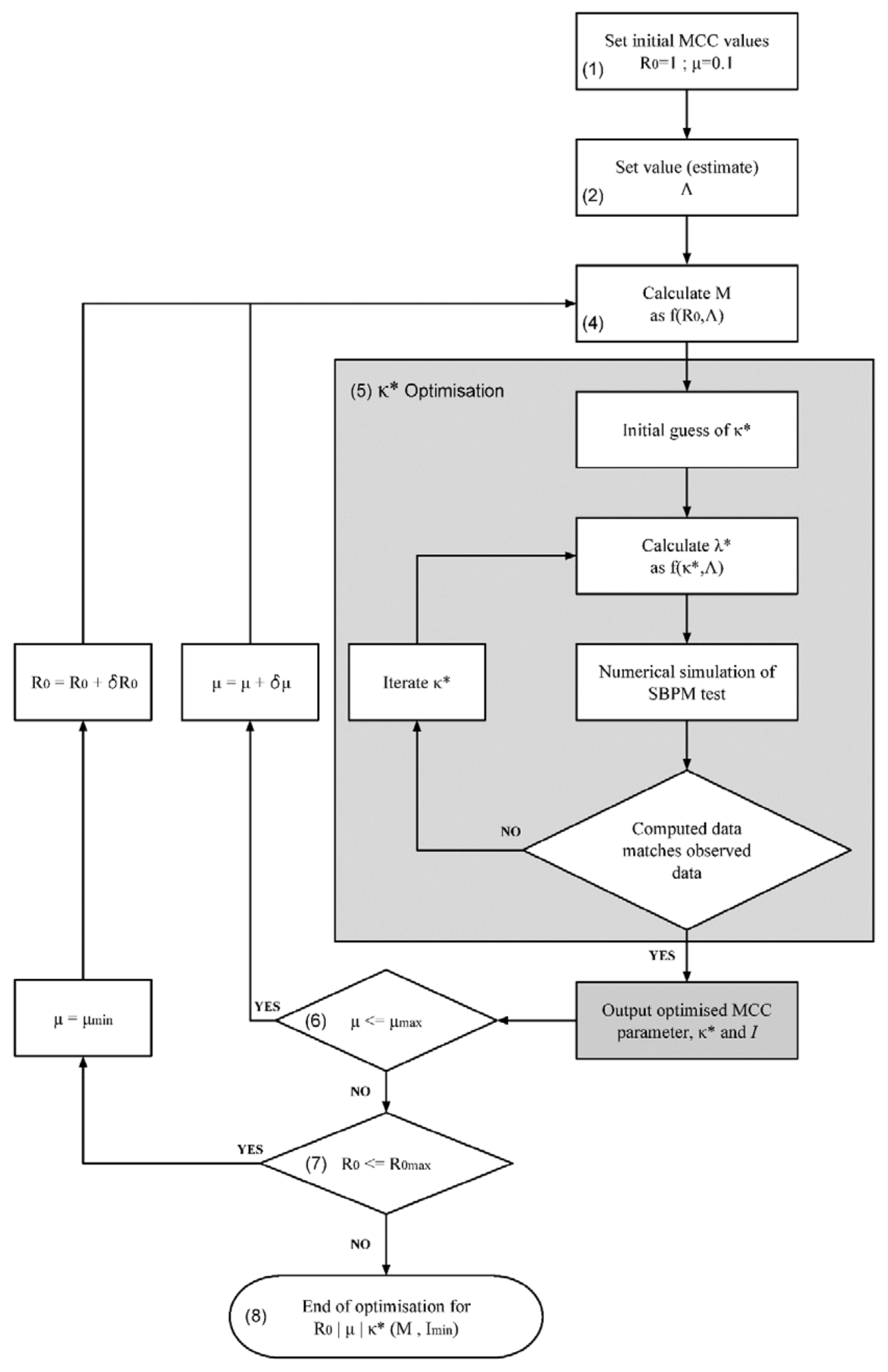

Figure 9: Nested single variable optimisation strategy to derive MCC parameters from SBPM test data developed in this study. 


\section{RESULTS}

283 The optimisation strategy described above and summarised in Figure 9, was applied to derive MCC parameters for the eight SBPM tests listed in Table 2.

285 The mean effective stress, $p$ ', is plotted against depth in Figure 10 for all eight tests. The undrained 286 shear strength, $s_{u}$ is plotted in Figure 11. The loading rate of the test, i.e. the rate of pressure increase 287 during the SBPM test, is noted in the figures. It can be seen from Figure 11 that higher loading rates result in higher undrained shear strengths, which may be an indication of viscous effects. The following values were set for the parametric sweep; $R_{0}{ }^{\min }=1, R_{0}{ }^{\max }=2, \delta R_{0}=0.1 \mu^{\min }=0.1, \mu^{\max }=0.4$ and $\delta \mu=$ 0.1. Once the optimal value for $R_{0}$ was identified using these search parameters, a second sweep was conducted in a narrow range of 0.1 either side of the optimal value of $R_{0}$ using $\delta R_{0}=0.02$.

\section{Initial mean effective stress, $p_{i}^{\prime}[\mathrm{kPa}]$}

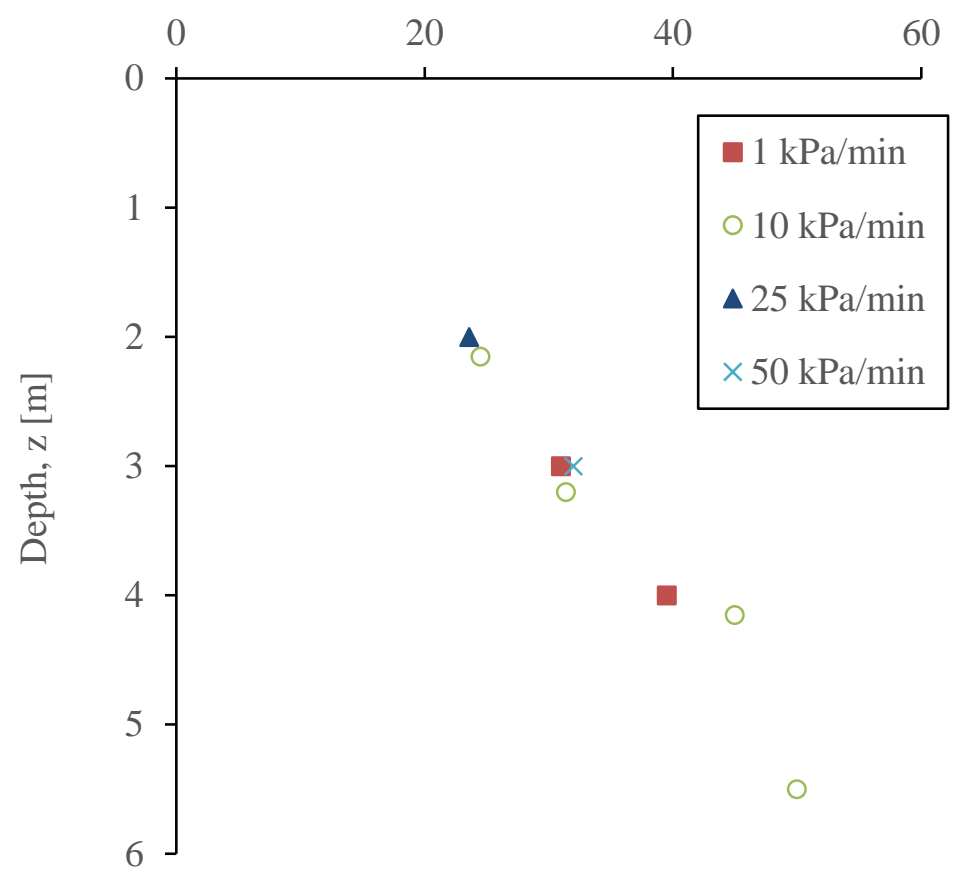




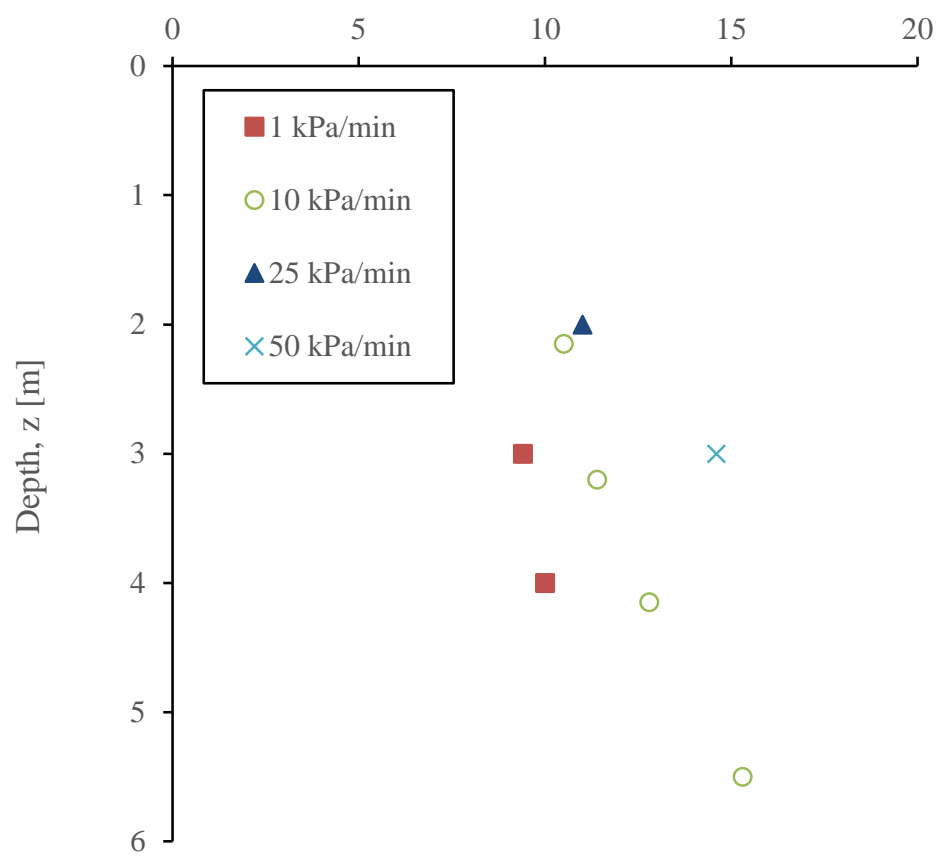

Figure 11: Undrained shear strength profile from the eight SBPM tests considered in this study.

296 Figure 12 plots the results from the shaded box in Figure 9, i.e. the minimum value of the objective 297 function, $I$, for each combination of $R_{0}$ and $\mu$ for optimised values of $\kappa^{*}$ for four selected tests. Similar 298 results were observed for the other four tests, but are not presented due to space restrictions. For each point in Figure 12, $\kappa^{*}$ was evaluated using the optimisation function fminbd in MATLAB. The function fminbd is based on the golden search section method and uses parabolic interpolation to find the minimum to a nonlinear function of a single bounded variable (MathWorks ${ }^{\circledR}$ 2010). During the optimisation process lower and upper bounds of $\kappa^{*}$ were specified as 0.001 and 0.05 .

Figure 13 plots the value of the objective function $(I)$ against the value of the composite unload-reload compression index $\kappa^{*}$ sampled by fminbd throughout the optimisation process for the full range of Poisson's ratio $\mu$ values with a single value of isotropic overconsolidation ratio $R_{0}=1.08$ for a single SBPM test at a depth of $5.50 \mathrm{~m}$. It can be seen that a very clear minimum exists for each value of $\mu$ and therefore fminbd converges rapidly to the optimal value of $\kappa^{*}$ (with other parameters fixed) in around 10 function evaluations. For each SBPM test, four values of $\mu$ and ten values of $R_{0}$ were trialled and $\kappa^{*}$ convergence typically required around 10 function evaluations. The total number of function 
310 evaluations for each test is therefore $10 \times 4 \times 10=400$. It can be seen from Figure 12 that the smallest

311 value of $\mu$ (i.e. $\mu^{\text {min }}$ ) results in the optimal or near optimal match to the data (i.e. smallest value of $I$ ).

312 This is consistent with a previous study that showed $\mu$ tended towards the minimum allowable value

313 when matching MCC parameters to undrained triaxial compression data [11]. It is therefore possible

314 that $\mu$ could be removed from the parametric sweep and the lowest acceptable value of $\mu$ adopted. This

315 would reduce the parametric sweep to around 100 function evaluations. The optimised parameters for each test are listed in Table 3.

Table 3: Optimised MCC parameters

\begin{tabular}{|c|c|c|c|c|c|c|c|}
\hline Borehole & $\begin{array}{c}\text { Depth } \\
{[\mathrm{m}]}\end{array}$ & $\begin{array}{c}\text { Loading } \\
\text { rate } \\
(\mathrm{kPa} / \mathrm{min})\end{array}$ & $\begin{array}{c}\mathrm{M} \\
{[-]}\end{array}$ & $\begin{array}{c}\Lambda \\
{[-]}\end{array}$ & $\begin{array}{c}\mu-] \\
\kappa^{*}\end{array}$ & $\begin{array}{c}R_{0} \\
{[-]}\end{array}$ & \\
\hline BH 2 & 2.15 & 10 & 1.276 & 0.92 & 0.1 & 0.0241 & 1.3 \\
\hline BH 2 & 3.20 & 10 & 1.22 & 0.92 & 0.1 & 0.0228 & 1.14 \\
\hline BH 2 & 4.15 & 10 & 0.91 & 0.92 & 0.1 & 0.0299 & 1.2 \\
\hline BH 2 & 5.50 & 10 & 1.2 & 0.92 & 0.1 & 0.0261 & 1.08 \\
\hline BH 3 & 2.00 & 25 & 1.56 & 0.92 & 0.1 & 0.0221 & 1.14 \\
\hline BH 3 & 3.00 & 50 & 1.65 & 0.92 & 0.1 & 0.0306 & 1.04 \\
\hline BH 4 & 3.00 & 1 & 0.99 & 0.92 & 0.1 & 0.0321 & 1.16 \\
\hline BH 4 & 4.00 & 1 & 0.76 & 0.92 & 0.1 & 0.0294 & 1.28 \\
\hline
\end{tabular}



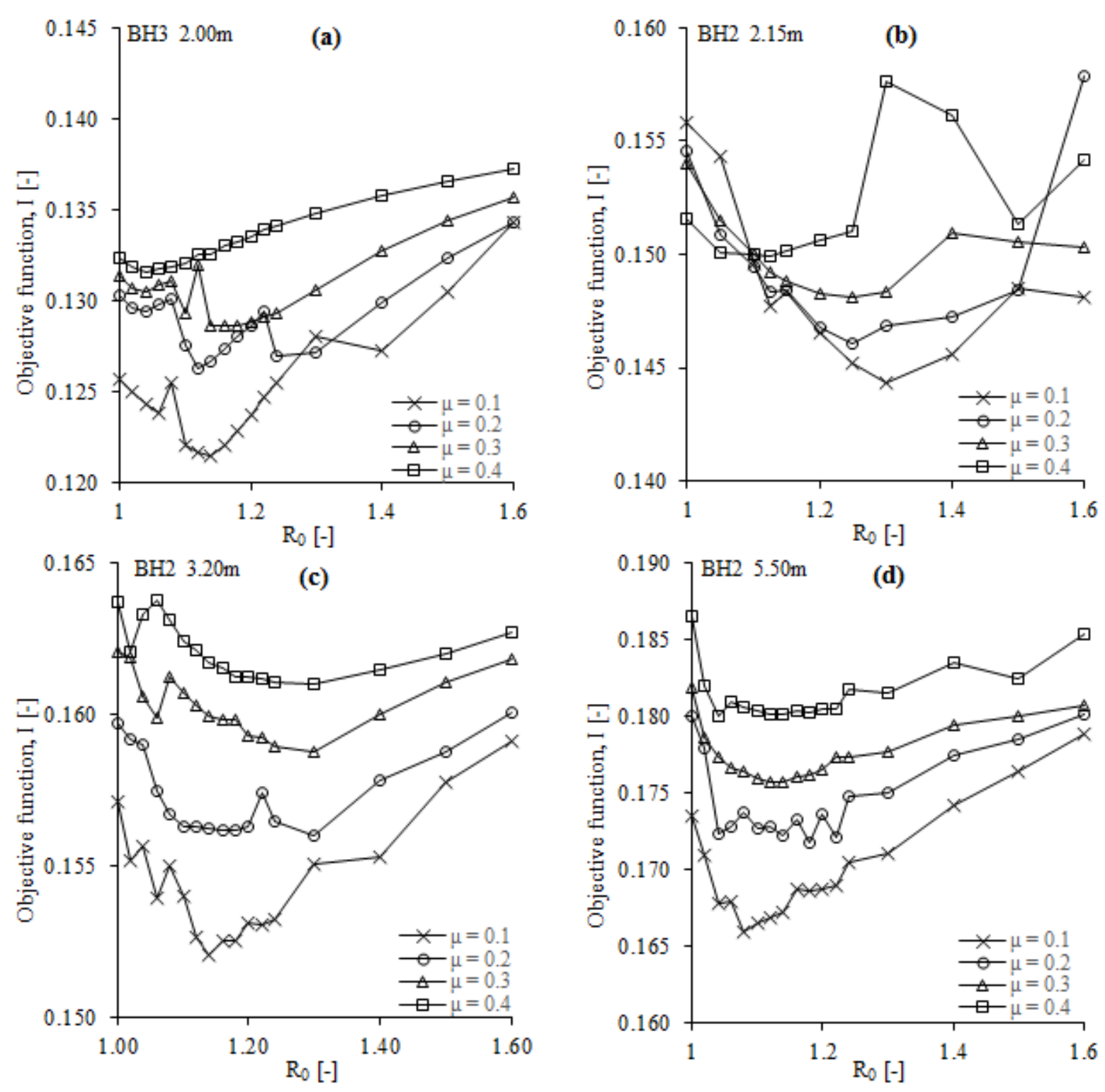

320 Figure 12: Objective function $I$ for a range of $\mu$ and $R_{0}$ values for selected tests; a) test BH3 2.00m; b) test BH2 2.15m; c) test BH 3.20m and d) test BH2 5.50m. 


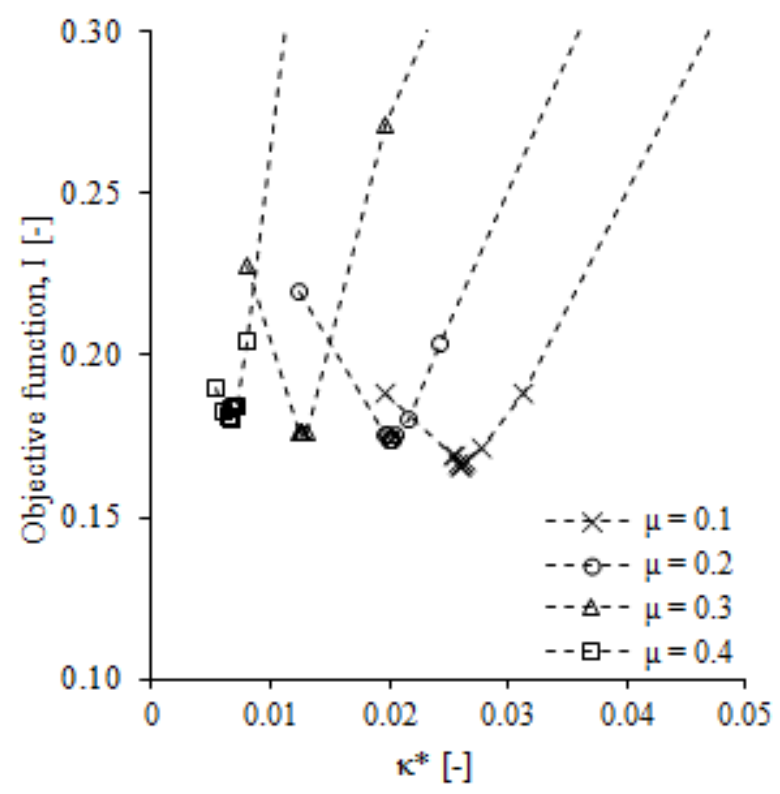

The stress-strain responses using the optimised MCC parameters are compared to four of the field tests in Figure 14. It can be seen that the MCC model generally gives a good match to the field data, although slightly under predicts the stiffness at lower strain levels. It is noted that as a fully coupled model is used in an undrained loading regime, volumetric strains are prevented by including the bulk stiffness of the pore fluid. The primary influence of Poisson's ratio is on the initial shear stiffness and the value of the initial shear stiffness increases as Poisson's ratio decreases (see Equation (4)). The fact that optimal value of $\mu$ was the lowest allowable value in each test indicates that the match to the data at low strain levels is limited by the constraint on Poisson's ratio. Theoretically, Poisson's ratio may range between 0.5 (infinite volumetric stiffness) and -1 (infinite shear stiffness). However, very low or negative Poisson's ratio will result in low or negative ratios of the change in horizontal and vertical effective stress in one-dimensional unloading or reloading. This is likely to be unacceptable in general applications of the model. It was therefore considered reasonable to limit the minimum value of Poisson's ratio to 0.1 . Very similar conclusions were drawn when fitting MCC parameters to triaxial compression data [11]. This highlights a limitation of the MCC model. How significant this limitation is when it comes to using the model to make field prediction is assessed in the following section of this 

subject to undrained vertical loading.
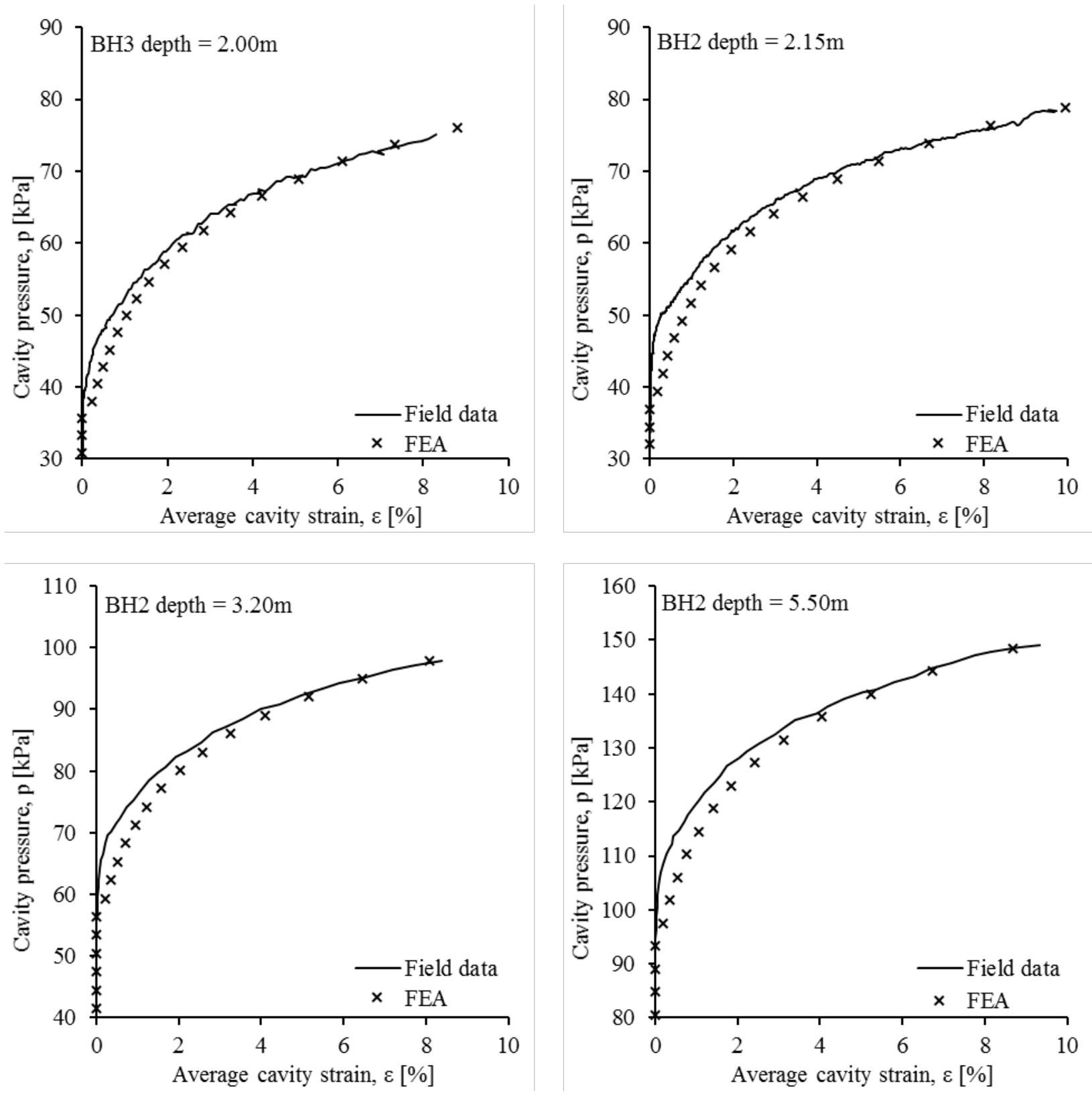

Figure 14: Examples of observed stress-strain response from SBPM tests compared with computed response using the optimised MCC parameter set. 
349 Figure 15 plots the shear modulus against depth, as defined by Equation (4) and the parameter values

350 in Table 3. Based on [20] the variation of shear modulus $(G)$ with depth $z$ was fitted using the following

351 equation

(16)

$$
G=G_{1} \cdot z^{\alpha}
$$

352

353 where the exponent $\alpha=0.6$ and $G_{1}=725(\mathrm{kPa})$ is the shear modulus at $z=1 \mathrm{~m}$. This form of power

354 law variation is considered reasonable for normally consolidated sand and soft clay [21]. The rigidity

355 index $\left(G / \mathrm{s}_{\mathrm{u}}\right)$ is plotted against depth in Figure 16. Except for the pressuremeter tests with the higher

356 loading rate of $50 \mathrm{kPa} / \mathrm{min}$, the rigidity index values are consistent with results from other studies at the

357 NFTF in Ballina [22].

Shear modulus, $G[\mathrm{kPa}]$

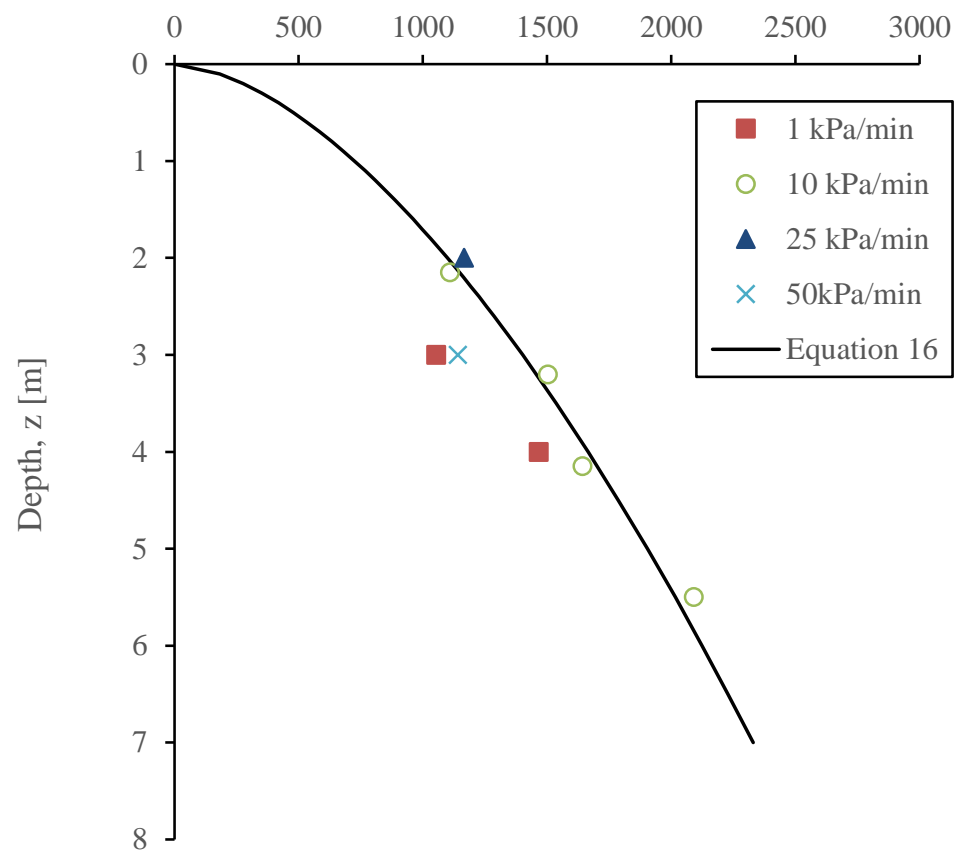

358

Figure 15: Shear modulus with depth calculated with optimised $\kappa^{*}$. 


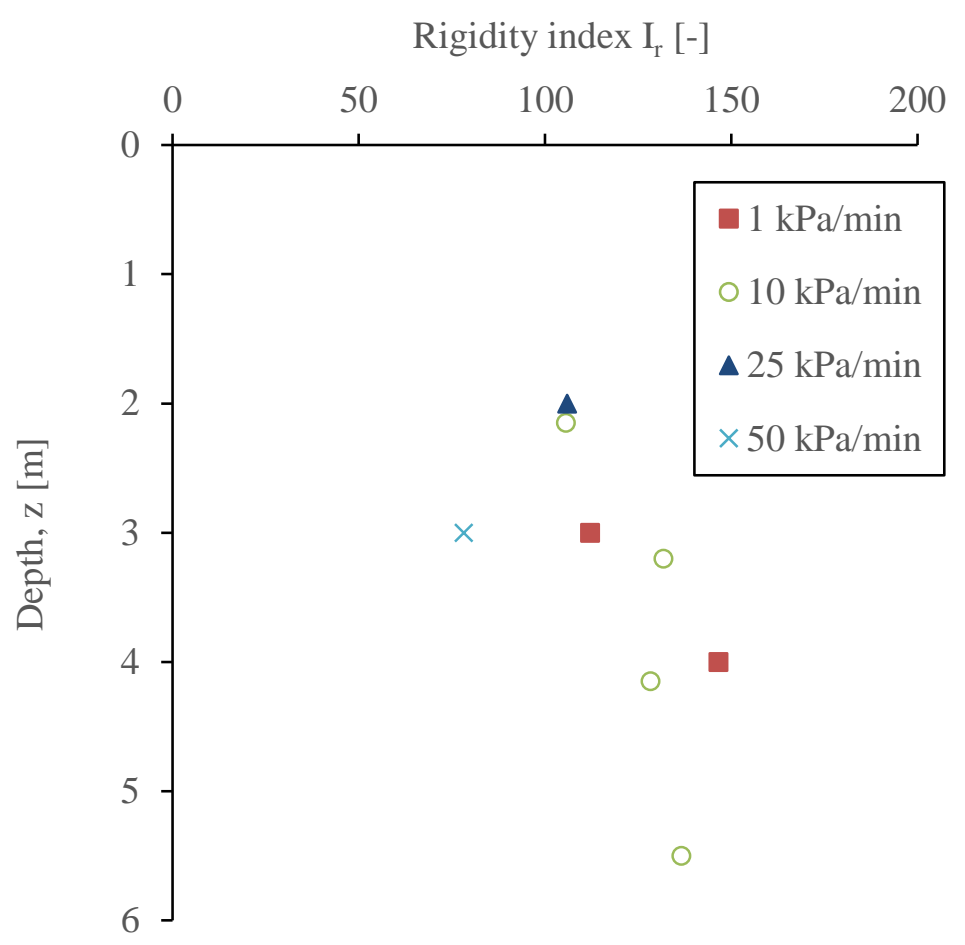

Figure 16: Rigidity index with depth predicted with optimised MCC parameter set.

\section{VALIDATION}

As shown in Figure 1, two large scale foundation load tests were carried out at the NFTF within $30 \mathrm{~m}$ of the pressuremeter tests that have been presented in this paper. Data from these foundation load tests provide an ideal opportunity to validate the parameter selection procedure described in this paper. The tests involved two $1.8 \mathrm{~m}$ square concrete foundations cast in an excavation $1.5 \mathrm{~m}$ below ground surface. The foundations were loaded undrained to failure while foundation displacements were recorded through surveying targets. A detailed description of the field testing is reported in the literature [23]. The numerical simulation of the shallow foundation was carried out with the Abaqus finite element software package. An axisymmetric finite element model was created with the radius of the circular foundation set to give the same area as the actual square foundations and the area of the gap between the edge of the foundation and the edge of the excavation also set equivalent to the field conditions

373 (Figure 17). Using an axisymmetric model to idealise a square foundation in this way has been shown

374 to have minimal effect on the bearing capacity of a shallow foundation under uniaxial vertical load [24]

375 (Gourvenec et al. 2006). The axisymmetric model was selected as a pragmatic approach, and one more 
likely to be adopted in engineering practice than a full 3D analysis. The mesh comprised using 4840 quadratic elements, determined through a sensitivity analysis to ensure sufficient mesh refinement was achieved. The base and circumferential boundaries were positioned sufficiently remote from the foundation so as not to influence the results.

The upper $1.5 \mathrm{~m}$ thick clayey silty sand was modelled as an elastic perfectly plastic material and the estuarine clay was modelled with in-built MCC material model (Clay plasticity) using four different layers. The parameters for the MCC model used in the analysis are presented in Table 4. These parameters are based on a pressuremeter loading rate of $10 \mathrm{kPa} / \mathrm{min}$. The loading rate of $10 \mathrm{kPa} / \mathrm{min}$ was chosen as data at this rate is available from a single borehole throughout the depth of the soft soil profile and therefore provides the most consistent set of parameters. This provides an opportunity to determine if $10 \mathrm{kPa} / \mathrm{min}$ is a suitable loading rate to predict the response of a shallow footing loaded to failure over a time period of approximately 1 hour..

Table 4: Optimised parameter set for MCC model used in foundation model

\begin{tabular}{|c|c|c|c|c|c|}
\hline $\begin{array}{c}\text { Depth } \\
{[\mathrm{m}]}\end{array}$ & $\begin{array}{c}\mathrm{M} \\
{[-]}\end{array}$ & $\begin{array}{c}\mathrm{R}_{0} \\
{[-]}\end{array}$ & $\begin{array}{c}\kappa^{*} \\
{[-]}\end{array}$ & $\begin{array}{c}\Lambda \\
{[-]}\end{array}$ & $\begin{array}{c}\mu \\
{[-]}\end{array}$ \\
\cline { 1 - 3 } $1.5-2.0$ & 1.33 & 1.28 & & & \multirow{2}{*}{0.023} \\
\cline { 1 - 2 } $2.0-3.0$ & 1.26 & 1.21 & 0.92 & 0.1 \\
\cline { 1 - 2 } $3.0-5.0$ & 1.22 & 1.12 & & & \\
\hline $5.0-10$ & 1.20 & 1.08 & & & \\
\hline
\end{tabular}

The simulation of the foundation tests comprised four major analysis steps:

1. Excavation of the foundation pit (unloading of the estuarine clay)

2. Construction of the foundation (reloading)

3. Consolidation period

4. Final undrained loading to failure

Observed and predicted load-settlement response to failure are shown in Figure 18. The excellent agreement between the measured and computed response demonstrates that the optimisation strategy 
set out in this paper for evaluating MCC parameters from SBPM data provides a practical and efficient approach to extrapolate SBPM data to predict the response of more complex undrained boundary value

400 problems.

401 A significant attribute of the procedure presented in this paper is that, once the vertical effective stress and pore pressure at the test location have been determined, the remainder of the parameter selection process is entirely automated. This means that there is less subjectivity and use of engineering judgement. The foundation data presented in Figure 18 was the subject of an international prediction exercise, where 50 groups of engineers on average over predicted the capacity of the foundation by $100 \%$ and the settlement at working loads by more than $1000 \%$. The primary reason for the poor predictions was attributed to the way in which engineers interpret geotechnical test data. Automated interpretation techniques, such as the one set out in the paper, are therefore critical in improving predictive performance.

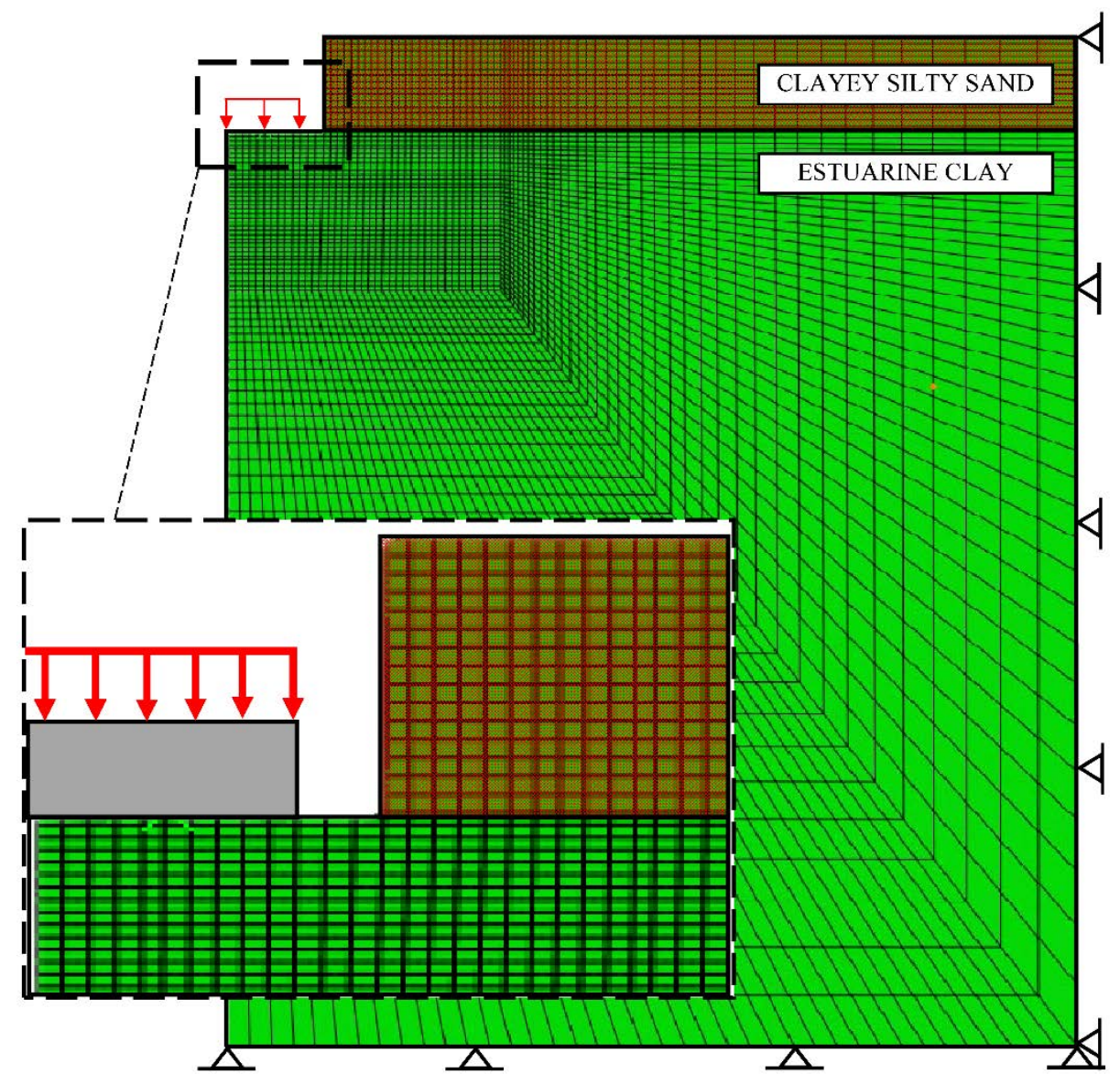




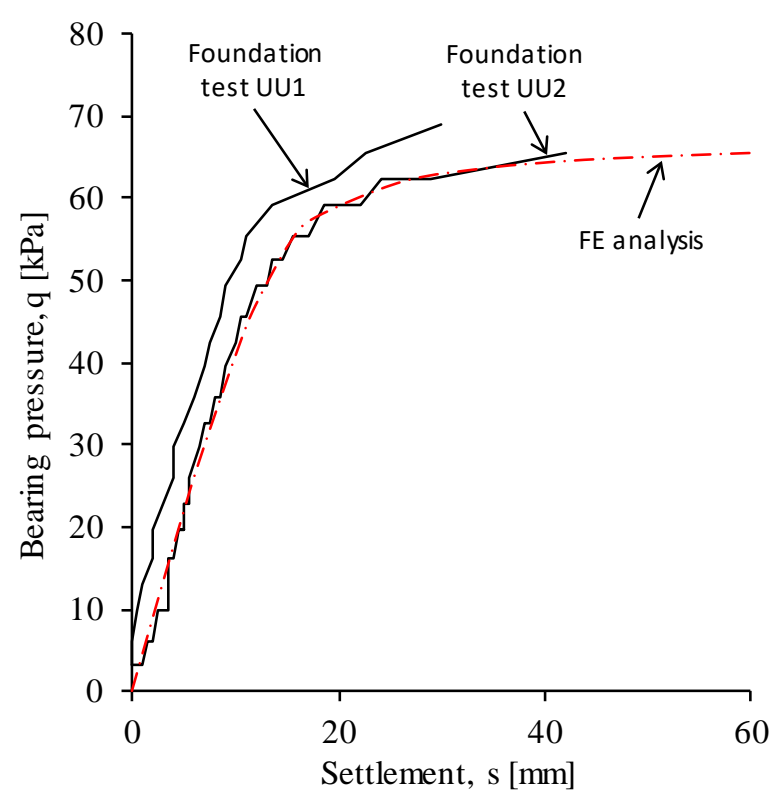

413 Figure 18: Observed and computed load-settlement response of shallow foundation tests conducted at the NFTF in Ballina, NSW.

\section{CONCLUSIONS}

416 A new, efficient, practical and automated strategy has been presented for deriving an optimised set of

417 Modified Cam Clay parameters from undrained self-boring pressuremeter test data using a strategic

418 combination of traditional interpretation methods, a parametric sweep and numerical optimisation

419 techniques.

420 The method was derived by examining the Modified Cam Clay formulation to identify groups of 421 parameters that control various features of undrained cavity expansion. Established methods are used to derive the initial mean effective stress and undrained shear strength, based on data from the start and

423 finish of the cavity pressure-cavity strain curve, respectively. This information is then used to constrain

424 the parameters that link effective stress and undrained shear strength. This limits the possible set of valid soil parameters and reduces the parameter search space allowing an efficient technique, combining a parametric sweep with a single variable optimisation, to automatically select the optimal, or near optimal, values for the remaining soil parameters. This approach has been developed into a powerful and versatile tool that automates parameter selection from pressuremeter data. The resulting parameters were found to depend on the rate of pressuremeter loading. Parameters derived from a pressuremeter 
loading rate of $10 \mathrm{kPa} / \mathrm{min}$ were found to provide an excellent back analysis of the undrained load-

431 settlement response of a $1.8 \mathrm{~m}$ square shallow foundation loaded to failure in approximately 1 hour.

432 Even though the process described is automated and removes subjectivity, it is fully auditable and engineers can use their expertise to critically assess the validity of the parameters that are derived

\section{ACKNOWLEDGEMENTS}

This work forms part of the activities of the Centre for Offshore Foundation Systems (COFS). Established in 1997 under the Australian Research Council's Special Research Centres Program. Supported as a node of the Australian Research Council's Centre of Excellence for Geotechnical Science and Engineering. This support is gratefully acknowledged.

\section{REFERENCES}

[1] Doherty JP, Gaone FM, Gourvenec S. Insights from a shallow foundation load-settlement prediction exercise. Comput Geotech 2017. doi:http://dx.doi.org/ 10.1016/j.compge.2017.05.009.

[2] Lehane BM. Vertically loaded shallow foundation on soft clayey silt. Proc Inst Civ Eng Geotech Eng 2003;156:17-26. doi:10.1680/geng.2003.156.1.17.

[3] Lehane B, Doherty JP, Schneider JA. Settlement prediction for footings on sand. 4th Int. Symp. Deform. Charact. Geomaterials, Atlanta: IOS press, The Netherlands; 2008, p. 133-50.

[4] Briaud J-L, Gibbens R. Large scale load tests and database of spread footings on sand. Fed Highw Adm Rep No FHWA-RD-97 1997.

[5] Klisinski M. Optimisation program for identification of constitutive parameters. Struct Res Ser 1987.

[6] Wood DM, Mackenzie NL, Chan AHC. Selection of parameters for numerical predictions. Predict Soil Mech Proc Wroth Meml Symp Oxford, 1992 1992:496-512.

[7] Mattsson H, Klisinski M, Axelsson K. Optimization routine for identification of model parameters in soil plasticity. Int J Numer Anal Methods Geomech 2001;25:435-72. doi:10.1002/nag.137. 
[8] Navarro V, Candel M, Barenca A, Yustres A, García B. Optimisation procedure for choosing Cam clay parameters. Comput Geotech 2007;34:524-31. doi:10.1016/j.compgeo.2007.01.007.

[9] Calvello M, Finno RJ. Selecting parameters to optimize in model calibration by inverse analysis. Comput Geotech 2004;31:411-25. doi:10.1016/j.compgeo.2004.03.004.

[10] Taborda D, Pedro A, Coelho P. Impact of input data on soil model calibration using Genetic Algorithms. Numer Methods Geotech Eng - Benz Nord 2010:69-74.

[11] Doherty JP, Alguire H, Muir Wood D. Evaluating modified Cam clay parameters from undrained triaxial compression data using targeted optimization. Can Geotech J 2012;49:128592.

[12] Doherty JP, Gourvenec S, Gaone FM, Kelly RB, Pineda JA, O’Loughlin C, Cassidy MJ, Sloan SW. A novel web based application for storing, managing and sharing geotechnical data, illustrated using the National soft soil field testing facility in Ballina, Australia. Comput Geotech 2017, 10.1016/j.compgeo.2017.05.007.

[13] Kelly RB, O'Loughlin CD, Bates L, Gourvenec S, Colreavy C, White DJ, et al. In situ testing at the National Soft Soil Field Testing Facility, Ballina, New South Wales. Aust Geomech 2014;50(4):13-26.

[14] Gaone FM, Doherty JP, Gourvenec S. Self-boring pressuremeter tests at the National Field Testing Facility, Ballina NSW. 5th Int. Conf. Geotech. Geophys. Site Characterisation, Gold Coast, Australia: 2016, p. 761-5.

[15] Systemes D. ABAQUS 6.14 User guide 2014.

[16] Roscoe KH, Burland JB. On the generalized stress-strain behaviour of wet clay 1968.

[17] Gibson R., Anderson WF. In situ measurement of soil properties with the pressuremeter. Civ Eng Public Work Rev 1961;56:615-8.

[18] Windle D, Wroth CP. The use of a self-boring pressuremeter to determine the undrained properties of clays. Gr Eng 1977;10:37-46.

[19] Wood DM. Soil behaviour and critical state soil mechanics. 1991. doi:https://doi.org/10.1017/CBO9781139878272.

[20] Doherty JP, Deeks AJ. Scaled boundary finite-element analysis of a non-homogeneous 
axisymmetric domain subjected to general loading. Int J Numer Anal Methods Geomech 2003;27:813-35. doi:10.1002/nag.300.

486 [21] Hardin BO, Drnevich VP. Shear modulus and damping in soils: design equations and curves. J Soil Mech Found Div ASCE 1972;98:667-92.

[22] Pineda JA, Suwal LP, Kelly RB, Bates L, Sloan SW. Characterisation of Ballina clay. Géotechnique 2016;66:556-77. doi:10.1680/jgeot.15.P.181.

[23] Gaone FM, Gourvenec S, Doherty JP. Large scale shallow foundation load tests on soft clay at the National Field Testing Facility (NFTF), Ballina, NSW, Australia. Comput Geotech 2017. doi:http://dx.doi.org/ 10.1016/j.compge.2017.05.008.

493

[24] Gourvenec S, Randolph MF, Kingsnorth O. Undrained bearing capacity of square and rectangular footings. Intern Journal of Geomech 2006. May/June, 6(3): 147-157. http://dx.doi.org/10.1061/(ASCE)1532-3641(2006)6:3(147)

496 